\title{
Isolation and identification of mold and yeast in medombae, a rice wine starter culture from Kompong Cham Province, Cambodia
}

\author{
${ }^{1,2^{*}}$ Chay, C., ${ }^{2}$ Dizon, E.I., ${ }^{3}$ Elegado, F.B., ${ }^{1}$ Norng, C., ${ }^{4}$ Hurtada, W.A. and ${ }^{2}$ Raymundo, L.C. \\ ${ }^{1}$ Royal University of Agriculture, Phnom Penh, Cambodia \\ ${ }^{2}$ Institute of Food Science and Technology, College of Agriculture and Food Science, University of the \\ Philippines Los Baños, College, Laguna - 4031, Philippines \\ ${ }^{3}$ The National Institute of Molecular Biology and Biotechnology (BIOTECH), University of the Philippines \\ Los Baños, College, Laguna-4031, Philippines \\ ${ }^{4}$ Institute of Human Nutrition and Food, College of Human Ecology, University of the Philippines Los \\ Baños, College, Laguna - 4031, Philippines
}

\section{Article history: \\ Received: 23 June 2017 Received in revised form: 19 July 2017 \\ Accepted: 20 July 2017 \\ Available Online: 21 July 2017}

Keywords:

Medombae,

Rice wine,

Instant starter culture ,

Mold and yeast

DOI:

http://doi.org/10.26656/ fr.2017.6.101

\begin{abstract}
Medombae is a dried starter culture used for traditional rice wine processing in Cambodia. However, studies on the role of mold and yeast present and their efficacy for rice wine fermentation are still limited. Cultural and morphological tests revealed that the isolated representative mold strains were isolated based on the method of identification used as Mucor spp and Rhizopus oryzae. On the other hand, the biochemical properties of the first yeast isolate using the Vitek 2 identification system and YST Card identification suggests its identity as Candida tropicalis. The second yeast strain examined for its morphological and cultural characteristic using agar slide technique, and its protein profile which was compared to the reference and sample protein masses using Biomerieux Vitek MS (MALD-TOF) showed the presence of Saccharomyces cerevisiae. The biochemical characteristics and cellular characteristics of the third yeast isolate as described by Lodder (1970) and Kreger-Van Rij (1984) confirmed its identity as Saccharomycopsis spp. The DNA test of identification of the isolates should be conducted to further confirm the identity of the isolates.
\end{abstract}

\section{Introduction}

A starter culture for rice fermentation is known as medombae in Cambodia. Spices, herbs, and a sweetener are ingredients commonly added also for dried starter preparation. Water is also added to the mixture and the previous starter was used as a source of inoculum at the rate of 1 to $2 \%$. After mixing thoroughly, the mixture is being shaped into balls manually and placed on layers of rice husks or dried rice straw for 3 days at room temperature, sun-dried, and used as a starter for the production of alcoholic beverages such as rice wine. This technique of making dried starter culture may have originated in one place and later spread throughout Southeast Asia. On the other hand, milled rice or millet or other starch-based cereals are the main substrates for rice wine fermentation.

One of the major problems faced by commercial brewers of rice wine in Cambodia, as with the brewers of other indigenous beverages, is the variable quality of the product. Variability in quality is strongly correlated with the type of mold and yeast present and quality control in the production of the traditional starter culture. Dung et al. (2005) developed a starter culture containing a defined mixed cultures of mold (Amylomyces rouxii) and yeast (Saccharomyces cerevisiae), and herbal extracts (from fennel and clove). However, starter culture in Cambodia is prepared using the traditional method, not the well-defined culture, and its production is limited only to some families because the recipe is kept secret and handed down from one generation to another. Thus, mold and yeast present in starter culture is unknown. Hence, this investigation isolated and identified dominant and useful mold and yeast in medombae from Kompong Cham province, Cambodia. 


\section{Materials and methods}

\subsection{Source of starter culture}

Dried, instant starter culture (medombae) (Figure 1A) obtained from Kompong Cham province, Cambodia was transported to the University of the Philippines Los Baños (UPLB), Philippines. Isolation and identification of essential mold and yeast were conducted in the Food Microbiology Laboratory, Food Science Cluster, College of Agriculture and The National Institute of Molecular Biology and Biotechnology (BIOTECH), University of the Philippines Los Baños (UPLB), College, Laguna 4031, Philippines.
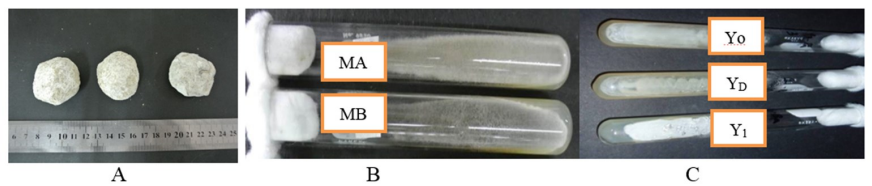

Figure 1. Cambodian dried starter culture (medombae) (A), pure culture of mold (B) and yeast (C) isolated from medombae

\subsection{Isolation of mold and yeast}

Isolation of mold and yeast from medombae samples was carried out. Ten grams $(10 \mathrm{~g})$ of the sample was added to $90 \mathrm{~mL}$ of $0.85 \% \mathrm{NaCl}$ solution. Series of dilution was done and $1 \mathrm{~mL}$ of appropriate dilution was plated using the standard pour plating technique. Malt Yeast Extract Agar (MYA) medium containing 0.2\% sodium propionate for yeast; and Potato Dextrose Agar (PDA) medium containing tartaric acid for mold were used for plating. The petri dishes were incubated upside down at $30^{\circ} \mathrm{C}$ for 48 hours and then the colonies of yeast and mold were counted and reported as colony forming units $\left./ \mathrm{mL}^{(\mathrm{CFU} \mathrm{mL}} \mathrm{mL}^{-1}\right)$.

Different types of dominant colonies were picked up and transferred to MYA slant for yeast, and PDA slant for mold.

\subsection{Purification of cultures}

Single colonies of representative isolates were purified following the dilution plating technique in the agar medium specified for a particular type of mold and yeast. Separated colonies were transferred again to the agar slants. Purification was done by streaking on plated agar and repeated two or three times or until pure cultures were obtained, as confirmed by microscopic examination, are obtained.

\subsection{Identification of microbial cultures}

Purified microbial cultures were identified through morphological, cultural, physiological and biochemical tests following the methods described by Alexopoulus et al. (1996), Samson et al. (1995), and Frazier and Westhoff (1998) for mold; and Kreger-van Rij (1984) and Lodder (1970) for yeast.

\section{Results and discussion}

Selection of representative colonies was based on the appearance of growth on PDA medium. Mold were identified through cultural and morphological test using an agar block technique. For yeast, aside from the above tests, physiological and biochemical properties were also examined.

\subsection{Identification of mold isolates}

Mold were successfully screened using a modification of the screening techniques described by Alexopoulus et al. (1996), Samson et al. (1995), and Frazier and Westhoff (1998). Two dominant mold strains coded MA and MB (Figure 1B) were chosen for identification.

MA mold isolate was observed white to creamishyellow cottony mycelia becoming brownish gray with aged; mycelium $\leq 10 \mathrm{~mm}$ in height; no soluble pigments and exudates produced; smooth, white to yellow on reverse side; $\leq 85 \mathrm{~mm}$ colony diameter; non-septated mycelium indicating that it belongs to Class Phycomycetes. Moreover, it has no sporangioles and characterized by the absence of stolon and rhizoids which are typical of Mucor spp.

Isolate $\mathrm{MB}$ is fast growing on PDA agar with cottony, aerial, white non-septate mycelium that turns grayish-white when aged; produces grayish-black spores and prominently forms rhizoid which is typical of Rhizopus spp. Cultural characteristics exhibited on different culture media (Table 1) as well as growth on Potato Dextrose Agar (PDA) at different temperatures were also used as the basis for the identification. Observation of growth was done for 7 days during incubation at $30^{\circ} \mathrm{C}$ or until fruiting bodies/spores were observed.

Cultural and morphological characteristics of the mold strains using the agar block technique revealed that both MA and MB mold isolates were non-septated which is the typical property of Class Phycomycetes. Further, MA has no sporangioles and stolons and characterized by the absence of rhizoid which is typical of Mucor spp. On the other hand, MB strain had a discernible rhizoid. Figure 2 shows the simple key for differentiation of Mucor spp and Rhizopus spp. 
Table 1. Cultural and morphological characteristics of the mold isolates

\begin{tabular}{|c|c|c|c|}
\hline \multirow{2}{*}{ Properties } & \multirow{2}{*}{$\begin{array}{l}\text { Culture } \\
\text { Medium }\end{array}$} & \multicolumn{2}{|r|}{ Isolate Code } \\
\hline & & MA & MB \\
\hline \multirow[t]{3}{*}{$\begin{array}{l}\text { Colony } \\
\text { Characteristics }\end{array}$} & $\begin{array}{l}\text { Potato } \\
\text { Dextrose } \\
\text { Agar } \\
\text { (PDA) }\end{array}$ & $\begin{array}{l}\text { White to creamish-yellow } \\
\text { cottony mycelia becoming } \\
\text { brownish gray with aged; } \leq 10 \\
\text { mm in height; no soluble } \\
\text { pigments and exudates } \\
\text { produces; smooth, white to } \\
\text { yellow reverse; } \leq 85 \mathrm{~mm} \text { colony } \\
\text { diameter }\end{array}$ & $\begin{array}{l}\text { White gray cottony mycelia that becomes dark brown-gray } \\
\text { with age; } \leq 10 \mathrm{~mm} \text { in height; no exudates and soluble } \\
\text { pigments produced; cream to yellow reverse; } \geq 90 \mathrm{~mm} \\
\text { colony diameter }\end{array}$ \\
\hline & $\begin{array}{l}\text { Czapek } \\
\text { Dox Agar } \\
\text { (CZA) }\end{array}$ & $\begin{array}{l}\text { White to creamish-yellow } \\
\text { cottony mycelia becoming } \\
\text { brownigh-gray with aged; } \leq 10 \\
\text { mm in height; no soluble } \\
\text { pigments and exudates } \\
\text { produced; smooth, white to } \\
\text { yellow reverse; } \leq 85 \mathrm{~mm} \text { colony } \\
\text { diameter }\end{array}$ & $\begin{array}{l}\text { White gray cottony mycelia that becomes dark brown-gray } \\
\text { with age; } \leq 10 \mathrm{~mm} \text { in height; no exudates and soluble } \\
\text { pigments produced; cream to yellow reverse; } \geq 90 \mathrm{~mm} \\
\text { colony diameter }\end{array}$ \\
\hline & $\begin{array}{l}\text { Malt } \\
\text { Extract } \\
\text { Agar } \\
\text { (MEA) }\end{array}$ & $\begin{array}{l}\text { Creamish-yellow cottony } \\
\text { mycelia becoming browning- } \\
\text { gray with age; } \leq 10 \mathrm{~mm} \text { in } \\
\text { height; no soluble pigments and } \\
\text { exudates produced; smooth, } \\
\text { white to yellow reverse; } \leq 85 \\
\text { mm colony diameter }\end{array}$ & $\begin{array}{l}\text { Dark brown-gray with age; } \leq 10 \mathrm{~mm} \text { in height; no exudates } \\
\text { and soluble pigments produced; cream to yellow reverse; } \\
\geq 90 \mathrm{~mm} \text { colony diameter }\end{array}$ \\
\hline $\begin{array}{l}\text { Cellular } \\
\text { Characteristics }\end{array}$ & & $\begin{array}{l}\text { Sporangia and sporagiophores } \\
\text { are light-colored and mostly } \\
\text { branch; sporangia are globose } \\
\text { with the absence of apophysis, } \\
45-50 \mu \mathrm{m} \text { in diameter; } \\
\text { chlamydospores are absent; } \\
\text { oidia are observed }\end{array}$ & $\begin{array}{l}\text { Sporangia and sporangiophores are dark pigmented, usually } \\
\text { dark-brown; mostly unbranched sporangiophores; stolons } \\
\text { are smooth or slightly rough, and yellow-brown; rhizoids } \\
\text { are brown in color; sporangia may arise directly from } \\
\text { stolons without rhizoids; sporangia may be globoso or sub- } \\
\text { globose, and are } 50-200 \mu \mathrm{m} \text { in diameter; columellae are } \\
\text { ovoid or globose, } 30-120 \mu \mathrm{m} \text { in diameter; sporangiospores } \\
\text { are globose or ovoid, and } 4-10 \mu \mathrm{m} \text { in diameter; } \\
\text { chlamydospores are present and may be globose, and } \\
\text { ellipsoidal or cylindrical, which measure } 10-35 \mu \mathrm{m} \text { or } 8-13 \\
\mathrm{x} 16-24 \mu \mathrm{m} \text { in diameter }\end{array}$ \\
\hline
\end{tabular}

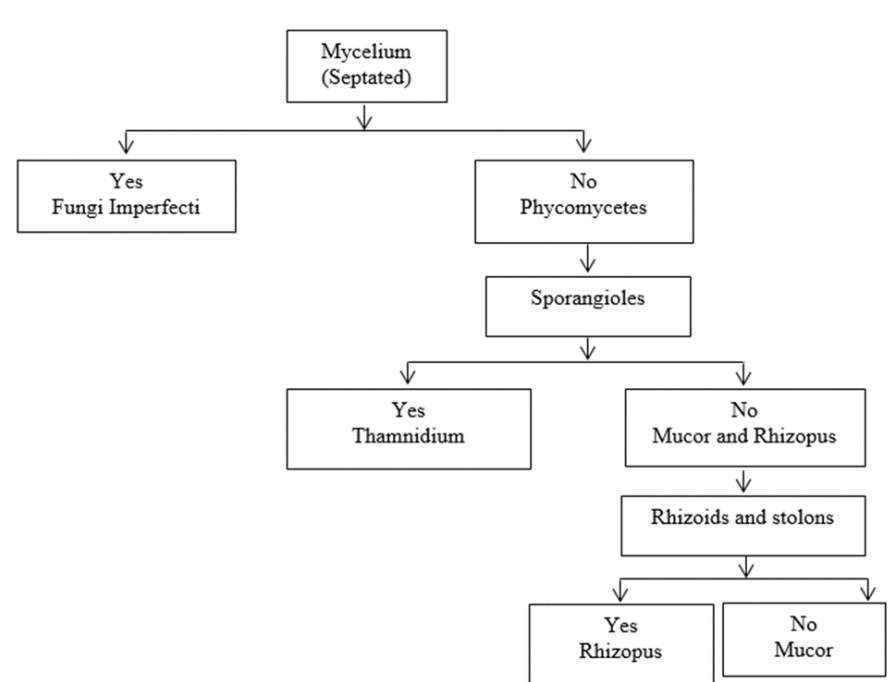

Figure 2. Simple key for differentiation of genera of mold under class Phycomycetes

MB strain is closely related to $R$. oligosporus, $R$. stolonifer and $R$. oryzae. However, chlamydospores of the isolate are not very abundant unlike the $R$. oligosporus, thus this specie was deleted from the choices. Furthermore, incubation of the mold isolates to $37^{\circ} \mathrm{C}$ showed good growth and this property differentiated the $R$. stolonifer from $R$. oryzae. Thus, the mold MB was identified as $R$. oryzae.

Based on the results of cultural and morphological tests, as summarized in Table 2, the dominant mold strains in medombae were identified as Mucor spp (coded MA) and Rhizopus oryzae (coded MB) (Figure 3). Several previous studies reported the presence of Mucor spp and Rhizopus spp (particularly R. oryzae) in various traditional starter cultures from Southeast Asian countries. Tamang et al. (1988), Hesseltine et al. (1988) and Thapa and Tamang (2004) reported the presence of mold namely $M$. circinelloides forma circinelloides, Mucor sp., R. chinensis, R. stolonifer, Rhizopus spp in marcha starter. Nikkuni et al. (1996) and Srestha et al. (2002) also stated that Rhizopus spp. were present in mana. Dwidjoseputro and Wolf (1970), Saono et al. (1974), Hadisepoetro et al. (1979), Hesseltine et al. (1988), Hesseltine and Ray (1988), Ardhana and Fleet 
(1989), Yokotsuka (1991) and Elegado and Fujio (1993) confirmed the presence of Mucor spp and Rhizopus spp in ragi starter from Indonesia. Rhizopus spp. and Mucor spp. were also found in bubod starter from the Philippines (Kozaki and Uchimura 1990; Hesseltine and Kurtzman 1990). Loogpang also contained Mucor and Rhizopus (Dhamcharee 1982; Uchinura et al. 1991). Rhizopus spp. was also found in nuruk starter from Korea (Kim 1968). Dung (2004), Dung et al. (2005, 2006, 2007), Lee and Fujio (1999) and Thanh et al. (2008) revealed that Rhizopus oryzae was isolated in banh men starter from Vietnam. Rhizopus was also found in chiu-yueh for lao-chao, a fermented rice product (Wei and Jong, 1983). Recently, Dizon et al. (2009, 2013) identified the dominant mold strains in bubod from the Philippines as Mucor spp. and $R$. oryzae.

Table 2. Summary of cultural and morphological characteristics of selected mold strains

\begin{tabular}{llll}
\hline \multirow{2}{*}{ Test } & \multirow{2}{*}{ Characteristics } & \multicolumn{2}{c}{ Strain Code } \\
\cline { 2 - 4 } & Form of & \multicolumn{1}{c}{ MA } & \multicolumn{1}{c}{ MB } \\
\hline growth & Cottony & Cottony \\
Morphologic & Brownish- & Grayish \\
al & Mycelium & Non-septated & Non-septated \\
& Color of & White to & Greyish to \\
& Fruiting & light brown & black \\
& body & Sporangiosp & $\begin{array}{l}\text { Sporangiosp } \\
\text { ores }\end{array}$ \\
Special Structure & No rhizoid & $\begin{array}{l}\text { Rhizoids } \\
\text { present } \\
\text { Rhizopus } \\
\text { oryzae }\end{array}$ \\
\hline
\end{tabular}
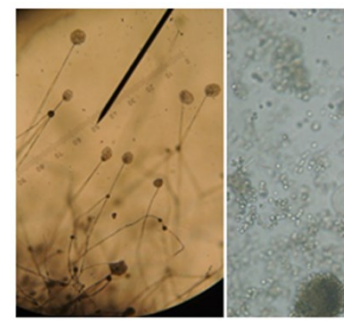

Mucor spp

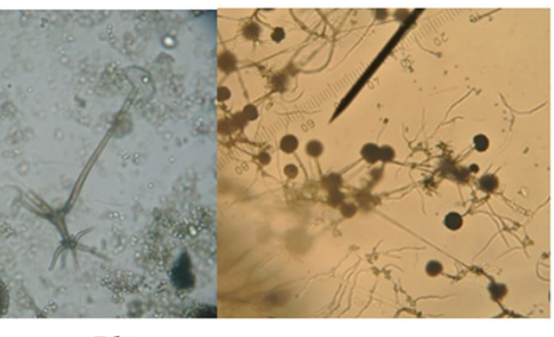

Figure 3. Photomicrograph of identified strains of mold from medombae

\subsection{Identification of yeast isolates}

Three yeast isolates, coded as $\mathrm{Yo}_{0}, \mathrm{Y}_{\mathrm{D}}$ and $\mathrm{Y}_{1}$ (Figure 1C), were chosen for identification based on their cultural, morphological, and physiological properties following the methods described by Lodder (1970) and Kreger-Van Rij (1984). The colony and cellular characteristics of yeast are presented in Table 3 .
The biochemical characteristics of Yo isolate were determined using the Vitek 2 identification system, and YST Card identification (Appendix A) and results revealed the identity as Candida tropicalis. On the other hand, the identity of $Y_{D}$ was determined through its morphological and cultural characteristic using agar technique (Appendix B). Moreover, its protein profile was compared to the reference and sample protein masses using BiomerieuxVitek MS (MALD-TOF) showing that $\mathrm{Y}_{\mathrm{D}}$ is a Saccharomyces cerevisiae. The biochemical and cellular characteristics of $Y_{1}$ isolate as described by Lodder (1970) and Kreger-Van Rij (1984) confirmed its identity as Saccharomycopsis spp. (Appendix C).

Results of various tests for identification of three yeast strains $\left(\mathrm{Y}_{\mathrm{o}}, \mathrm{Y}_{\mathrm{D}}\right.$, and $\left.\mathrm{Y}_{1}\right)$ isolated from medombae suggest that they are Candida tropicalis, Saccharomyces cerevisiae and Saccharomycopsis spp. based on the method of identification used, respectively (Figure 4). This study agreed with Tsuyoshi et al. (2005) and Thapa and Tamang (2004) who also identified the presence of S. cerevisiae in marcha. S. cerevisiae has been selected for the production of defined granulated starters for the production of high-quality Vietnamese rice wine (Dung 2004; Dung et al. 2005). In addition, Sm. fibuligera was also found as the most dominant yeast in marcha (Tamang and Sarkar 1995). Thapa and Tamang (2004) reported that saccharifying activities are mostly shown by Rhizopus spp. and Sm. fibuligera, whereas liquefying activities are shown by Sm. fibuligera and $S$. cerevisiae. Uchimura et al. (1990) isolated Saccharomycopsis in poo or phab (marcha of Bhutan). Yeast associated with ragi was Saccharomycopsis (Dwidjoseputro and Wolf 1970; Saono et al., 1974; Hadisepoetro et al., 1979; Hesseltine et al., 1988; Hesseltine and Ray, 1988; Ardhana and Fleet, 1989; Yokotsuka, 1991). S. cerevisiae and Sm. fibuligera have also been reported to be present in bubod (Kozaki and Uchimura, 1990; Dizon et al., 2009, 2013); however, Sm. fibuligera is the dominant amylolytic yeast in bubod (Hesseltine and Kurtzman, 1990). Loogpang is an ethnic amylolytic starter from Thailand, which is commoly used to prepare alcoholic drinks and vinegar. Species of yeast present in loogpang are Sm. fibuligera

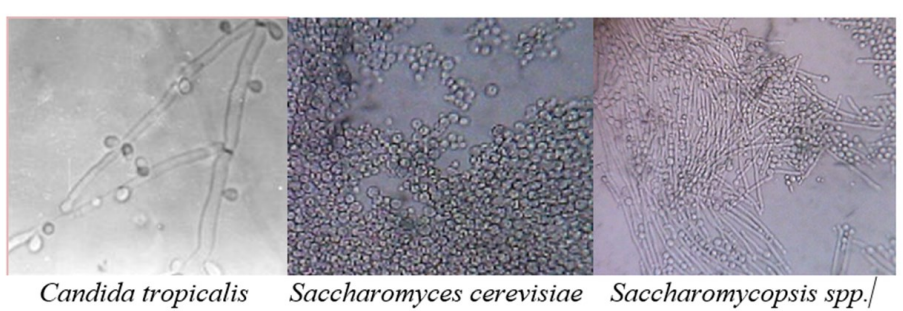

Figure 4. Photomicrograph of isolated yeast strains from medombae 
Table 3. Morphological characteristics of the yeast isolates

\begin{tabular}{|c|c|c|}
\hline Isolate code & Colony Characteristics & Cellular Characteristics \\
\hline $\mathrm{Y}_{\mathrm{O}}$ & $\begin{array}{l}\text { White, circular, smooth, dull, opaque, convex to um- } \\
\text { bonate, entire margin; } 3.0 \mathrm{~mm} \text { colony diameter }\end{array}$ & $\begin{array}{l}\text { Sub-globose to globose cells arranged in singles, } \\
\text { pairs, and cluster; exhibits unipolar and bipolar bud- } \\
\text { ding; } 3.0-6.0 \mu \mathrm{m} \text { diameter }\end{array}$ \\
\hline$Y_{D}$ & $\begin{array}{l}\text { White, circular, rough, dull, opaque, convex to umbo- } \\
\text { nate, entire to erose margin; } 2-3 \mathrm{~mm} \text { colony diameter }\end{array}$ & $\begin{array}{l}\text { Globose to sub-globose cells arranged in singles, } \\
\text { pairs, and clusters; exhibits unipolar budding; 3-6 } \mu \mathrm{m} \\
\text { diameter }\end{array}$ \\
\hline $\mathrm{Y}_{1}$ & $\begin{array}{l}\text { White, circular, rough, dull, opaque, convex to umbo- } \\
\text { nate, entire to erose margin; } 3.0 \mathrm{~mm} \text { colony diameter }\end{array}$ & $\begin{array}{l}\text { Sub-globose to cylindrical cells arranged in singles, } \\
\text { and clusters; exhibits unipolar budding; } 2.0->30.0 \mu \mathrm{m} \\
\text { length; } 2.0-5.0 \mu \mathrm{m} \text { width }\end{array}$ \\
\hline
\end{tabular}

and Saccharomyces (Dhamcharee, 1982; Uchinura et al., 1991). Sm. fibuligera of loogpang showed high glucoamylase activity (Sukhumavasi et al., 1975). Sm. fibuligera, S. cerevisiae and Candida tropicalis have been isolated in men (Dung et al., 2005, 2006, 2007). Sm. fibuligera and $S$. cerevisiae were also present in banh men (Thanh et al., 2008).

\section{Conclusion and recommendation}

Identified dominant mold and yeast from medombae are Rhizopus oryzae and Mucor spp. for mold; Candida tropicalis, Saccharomyces cerevisiae and Saccharomycopsis spp. for yeast. Mold strains (R. oryzae, Mucor spp) and one strain of special yeast (Saccharomycopsis spp) are known for their starch saccharification capability while yeast strain, $S$. cerevisiae for its alcohol production. It is however recommended that DNA test be done in the future studies to confirm the identity of the isolates.

\section{Acknowledgments}

The authors extend their gratitude and appreciation to the Southeast Asian Regional Center for Graduate Study and Research in Agriculture (SEARCA), Philippines, for the scholarship grant; to the Royal University of Agriculture (RUA) for the opportunity and providing valuable assistance in the completion of the study; medombae processors in Kompong Cham province, and The National Institute of Molecular Biology and Biotechnology (BIOTECH) at UP Los Baños, Philippines for the assistance in the identification of the mold and yeast isolates.

\section{References}

Alexopoulus, C.J., Mims, C.W. and Blackwell M. (1996). Introductory Mycology. 4th ed., p. 869. New York; John Wiley and Sons, Inc.

Ardhana, M.M. and Fleet, G.H. (1989). The microbial ecology of tapé ketan fermentation. International Journal of Food Microbiology, 9, 157-65.

Dhamcharee, B. (1982). Traditional fermented food in Thailand. In Saono, S., Winarno, W.J., Karjarki, D. (Eds.). Traditional food fermentation as industrial resources in ASCA countries, p. 85-90. Jakarta: The Indonesian Institute of Science (LIPI).

Dizon, I.E., Olivia, M.D.R., Marissa, V.R., Evelyn, H.B. and Amelia, V.M. (2009). Standardization of starter culture for rice wine (Tapuy) processing. Terminal Report. Food Science Cluster. UP Los Banos. Philippines.

Dizon, E.I, Olivia, M.D.R., Rona, C.L. and Vanniza, C.I. (2013). Establishment of microbial succession of starter culture for rice wine (Tapuy) processing. Quarterly Report. Food Science Cluster. UP Los Banos. Philippines.

Dung, N.T.P. (2004). Defined fungal starter granules for purple glutinous rice wine. Wageningen, The Netherlands: Wageningen University, DPhil thesis.

Dung, N.T.P., Rombouts, F.M. and Nou, M.J.R. (2005). Development of defined mixed-culture fungal fermentation starter granulates for controlled production of rice wine. Innovative Food Science Emerging Technologies, 6, 429-441.

Dung, N.T.P., Rombouts, F.M. and Nou, M.J.R. (2006). Functionality of selected strains of mold and yeast from Vietnamese rice wine starters. Food Microbiology, 23, 331-340.

Dung, N.T.P., Rombouts, F.M. and Nou, M.J.R. (2007). Characteristics of some traditional Vietnamese starch -based rice wine fermentation starters (men). LWT, 40, 130-135.

Dwidjoseputro, D. and Wolf, F.T. (1970). Microbiological studies of Indonesian fermented foodstuffs. Mycopathologia et Mycologia Applicata, $41,211-222$.

Elegado, F.B. and Fujio, Y. (1993). Polygalacturonase production by Hizopus spp. Journal of General and Applied Microbiology, 39, 409-418. 
Frazier, W.C. and Westhoff, D.C. (1998). Food Microbiology. 4th ed., p. 539. New York: McGraw Hill Book Co., Inc.

Hadisepoetro, E.S.S., Takada, N. and Oshima, Y. (1979). Microflora in ragi and usar. Journal Fermentation Technology, 57, 251-259.

Hesseltine, C.W. and Kurtzman, C.P. (1990) Yeast in amylolytic food starters. Anales del Instituto de Biologa, Universidad National. Automoma de Mexico. Serie Botanica, 60, 1-7.

Hesseltine, C.W. and Ray, M.L. (1988) Lactic acid bacteria in murcha and ragi. Journal Applied Bacteriology, 64, 395-401.

Hesseltine, C.W., Rogers, R. and Winarno, F.G. (1988) Microbiological studies on Amylolytic Oriental fermentation starters. Mycopathologia, 101, 141-55.

Kim, C.J. (1968) Microbiological and enzymological studies on Takju brewing. Journal Korean Agriculture Chemistry Societies, 10, 69-79.

Kozaki, M. and Uchimura T. (1990). Microorganisms in Chinese starter "bubod" and rice wine "tapuy" in the Philippines. Japan Brewering Society Japan, 85(11), 818-24.

Kreger-Van Rij, N.J.W. (1984). The Yeast. $3^{\text {rd }}$ revision and enlarged, p. 1081. Amsterdam: Elsevier Science Publishers.

Lee, A.C. and Fujio Y. (1999). Microflora of banh men, a fermentation starter from Vietnam. World Journal Microbiology Biotechnology, 15, 51-55.

Lodder, J. (1970). The Yeast. A taxonomic study. $2^{\text {nd }}$ ed., p. 1123. Amsterdam: North-Holland Publishing Co.

Nikkuni, S., Karki, T.B., Terao, T. and Suzukic C. (1996). Microflora mana, a Nepalese rice koji. Journal Ferment Bioengineering, 81(2), 168-170.

Saono, S., Gandja I., Basuki, T. and Karsono, H. (1974). Mycoflora of ragi and some other traditional fermented foods of Indonesia. Annales Bogoriensis, 4, 187-204.

Sukhumavasi, J., Kato, K. and Harada, T. (1975). Glucoamylase of a strain of Endomycopsis fibuligera isolated from mould bran (loogpang) of Thailand. Journal of Fermentation Technology. 53(8), 559-65.

Tamang, J.P., Sarkar, P.K. and Hesseltine, C.W. (1988). Traditional fermented foods and beverages of Darjeeling and Sikkim-a review. Journal Science Food Agriculture, 44, 375-85.

Tanang, J.P. and Sarkar, P.K. (1995). Microflora of murcha: an amylolytic fermentation starter. Microbiology Laboratory, Centre for Life Sciences,
University of North Bengal, Siliguri 734430, India. Microbios, 81, 115-122.

Thanh, V.N., Mai, L.T. and Tuan, D.A. (2008). Microbial diversity of traditional Vietnamese alcohol fermentation starters (banh men) as determined by PCR-mediated DGGE. International Journal Food Microbiology, 128, 268-373.

Thapa, S. and Tamang, J.P. (2004). Product characterization of kodo jaanr: fermented finger millet beverage of Himalayas. Food Microbiology, 21, 617-622.

Tsuyoshi, N., Fudou, R., Yamanaka, S., Kozaki, M., Tamang, N., Thapa, S. and Tamang, J.P. (2005). Identification of yeast strains isolated from marcha in Sikkim: A microbial starter for amylolytic fermentation. International Journal Food Microbiology, 99, 135-146.

Uchimura, T., Kojima, Y. and Kozaki, M. (1990). Studies on the main saccharifying microorganism in the Chinese starter of Bhutan 'chang poo'. Journal Brewery Societies Japan, 85(12), 881-887.

Wei, D. and Jong, S. (1983). Chinese rice pudding fermentation: fungal flora of starter cultures and biochemical changes during fermentation. Journal Fermentation Technology, 61(6), 573-579.

Yokotsuka, T. (1991). Non proteinaceous fermented foods and condiments prepared with koji mold. In Arora DK, Mukerji KG, Marth EH, Editors. Handbook of applied mycology. Vol. 3., p. 292-328. New York: Marcel Dekker. 
Appendix A. Biochemical characteristics of the yeast isolate

Tests using the Vitek 2 identification system, YST Card for Yo

Substrates for tests

L-Lysine Arylamidase

L-Malate Assimilation

Leucine Arylamidase

Arginine

Erythritol Assimilation

Glycerol Assimilation

Tyrosine Arylamidase

Beta-N-Acetyl-Glucosaminidase

Arbutin Assimilation

Amygdalin Assimilation

D-Galactose Assimilation

Lactose Assimilation

Methyl-Alpha-D-Glucopyranoside Assimilation

D-Cellobiose Assimilation

Gamma-Glutamyl-Transferase

D-Maltose Assimilation

D-Raffinose Assimilation

PNP-N-Acetyl-Beta-D-Galactosaminidase 1

D-Mannose Assimilation

D-Melibiose Assimilation

D-Melezitose Assimilation

L-Sorbose Assimilation
Yo

$+\quad$ Saccharose/Sucrose Assimilation

$+\quad$ Urease

$+\quad$ Alpha-Glucosidase

- D-Turanose Assimilation

- $\quad$ D-Trehalose Assimilation

- Nitrate Assimilation

- $\quad$ L-Aracturonate Assimilation

- $\quad$ Esculin Hydrolysis

- L-Glutamate Assimilation

$+\quad$ D-Xylose Assimilation

- DL-Lactate Assimilation

$+\quad$ Acetate Assimilation

- Citrate (sodium salt) Assimilation

- Glucuronate Assimilation

$+\quad$ L-Proline Assimilation

- 2-Keto-D-Gluconate Assimilation

- N-Acetyl-Glucosamine Assimilation

$+\quad$ D-Gluconate Assimilation

- $\quad$ L-Rhamnose Assimilation

$+\quad$ Xylitol Assimilation
- D-Sorbitol Assimilation

Yo

$+$

$+$

$+$

Appendix B. Comparison of the reference and sample protein masses for $Y_{D}$

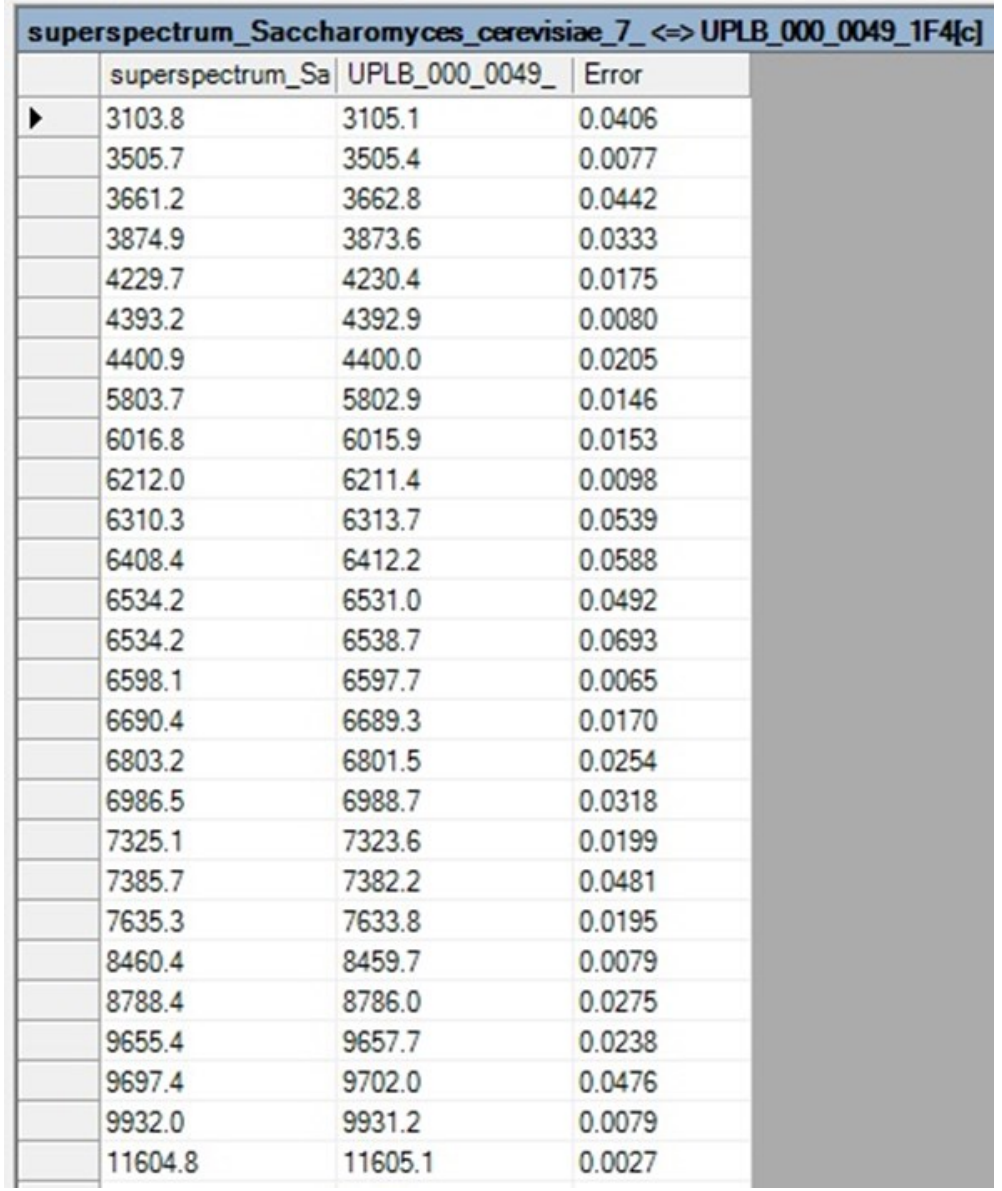


Appendix C. Tests using the Vitek 2 identification system, YST Card for Y1

Substrates for tests

L-Lysine Arylamidase

L-Malate Assimilation

Leucine Arylamidase

Arginine

Erythritol Assimilation

Glycerol Assimilation

Tyrosine Arylamidase

Beta-N-Acetyl-Glucosaminidase

Arbutin Assimilation

Amygdalin Assimilation

D-Galactose Assimilation

Gentiobise Assimilation

D-Glucose Assimilation

Lactose Assimilation

Methyl-Alpha-D-Glucopyranoside Assimilation

D-Cellobiose Assimilation

Gamma-Glutamyl-Transferase

D-Maltose Assimilation

D-Raffinose Assimilation

PNP-N-Acetyl-Beta-D-Galactosaminidase 1

D-Mannose Assimilation

D-Melibiose Assimilation

D-Melezitose Assimilation
Y1

- $\quad$ L-Sorbose Assimilation

$+\quad$ L-Rhamnose Assimilation

$+\quad$ Xylitol Assimilation

- D-Sorbitol Assimilation

- Saccharose/Sucrose Assimilation

- Urease

$+\quad$ Alpha-Glucosidase

- D-Turanose Assimilation

- D-Trehalose Assimilation

$+\quad$ Nitrate Assimilation

- L-Aracturonate Assimilation

$+\quad$ Esculin Hydrolysis

$+\quad$ L-Glutamate Assimilation

- D-Xylose Assimilation

- DL-Lactate Assimilation

- Acetate Assimilation

- Citrate (sodium salt) Assimilation

$+\quad$ Glucuronate Assimilation

- L-Proline Assimilation

- 2-Keto-D-Gluconate Assimilation

$+\quad$ N-Acetyl-Glucosamine Assimilation

- D-Gluconate Assimilation 